\title{
Comparison of sputum induction and bronchoscopy in diagnosis of sputum smear-negative pulmonary tuberculosis: a systemic review and meta-analysis.
}

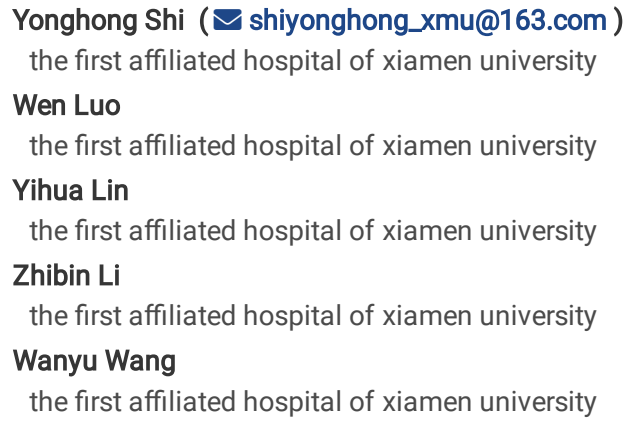

Version of Record: A version of this preprint was published at BMC Pulmonary Medicine on May 25th, 2020. See the published version at https://doi.org/10.1186/s12890-020-01192-w. 


\section{Abstract}

Background and Objectives: Pulmonary tuberculosis is one of the most common infectious diseases worldwide. Patients with suspected pulmonary tuberculosis with negative smear are recommended to undergo further tests including sputum induction and bronchoscopy. Our study is aimed to compare sputum induction and bronchoscopic specimens in the diagnosis of sputum smear-negative pulmonary tuberculosis.

Method: PubMed, Web of Science, Cochrane Library and Embase were searched for eligible studies. The pooled sensitivities (SEN), specificities (SPE), positive likelihood ratio (PLR), negative likelihood ratio (NLR), diagnostic odds ratio (DOR) and 95\% confidence interval (Cls) were constructed, and the areas under the curves (AUCs) were calculated.

Results: Five studies with a total number of 586 cases were included. For mycobacterial culture, the SEN and SPE of sputum induction were 0.72 (95\% $\mathrm{Cl}$, 0.66 $0.77)$ and $1.00(95 \% \mathrm{Cl}, 0.99-1.000)$ respectively, whereas the SEN and SPE of bronchoscopy were $0.70(95 \% \mathrm{Cl}, 0.64-0.75)$ and $1.00(95 \% \mathrm{Cl}, 0.99-1.00)$ respectively. Sputum induction had a similar $\mathrm{AUC}(0.9564, \mathrm{SE}=0.0749)$ with bronchoscopy $(0.8618, \mathrm{SE}=0.1652)(P=0.602)$. For specimen of acid-fast bacilli smear, the SEN and SPE of sputum induction were 0.35 (95\% Cl, 0.29-0.42) and 0.99(95\% Cl, 0.96-1.00) respectively, whereas the SEN and SPE of bronchoscopy were $0.38(95 \% \mathrm{Cl}, 0.32-0.45)$ and $0.99(95 \% \mathrm{Cl}, 0.96-1.00)$ respectively. Sputum induction had a familiar AUC (0.6016) with bronchoscopy $(0.8163)(P=0.792)$.

Conclusions: For the diagnosis of sputum smear-negative pulmonary tuberculosis, the diagnosis yield of sputum induction and bronchoscopy is similar.

\section{Introduction}

Pulmonary tuberculosis is one of the most common infectious disease worldwide and also one of the top 10 causes of death, especially in developing countries ${ }^{1}$. Early diagnosis is the most effective pulmonary tuberculosis control strategy because the early appropriate treatment renders these patients noninfectious and interrupts the chain of disease transmission. Acid-fast bacilli in sputum is recommended as the preliminary diagnostic method by the World Health Organization (WHO). However, the sensitivity of this method is low and the value in patients who cannot produce sputum spontaneously is very little ${ }^{2,3}$. It follows that the active respiratory specimens collection is an important strategy to early diagnosis of pulmonary tuberculosis ${ }^{4}$.

Sputum induction and/or bronchoscopy are commonly used for the diagnosis in patients with suspected tuberculosis who do not produce sputum or have a negative acid-fast bacilli smear from spontaneous sputum. Sputum induction is a safe and effective method in obtaining specimens for acid-fast bacilli smear and mycobacterial culture ${ }^{5}$. In areas where bronchoscopy is not readily available, sputum induction offers an alternative or additional approach to the diagnosis of sputum smear-negative pulmonary tuberculosis ${ }^{6}$. Bronchoscopy is more invasive, more expensive, and less-tolerated than sputum induction, but bronchoscopy can provide specimens from the lesion area of the lung.

Over the past decade, several studies ${ }^{5-9}$ have described the diagnosis yield of sputum induction in comparison with bronchoscopy in the sputum smearnegative pulmonary tuberculosis. Because of the heterogeneous populations and small sample sizes, the results of these studies were variable. This study is aimed to compare the sensitivity and specificity of sputum induction and bronchoscopy in the diagnosis of sputum smear-negative pulmonary tuberculosis by the method of meta-analysis. ${ }^{5-9}$

\section{Methods}

This study was performed according to the Preferred Reporting Items for Systematic Reviews and Meta-Analyses (PRISMA) statement. The protocol for this meta-analysis is available in PROSPERO (CRD42019133766).

\section{Search for trials}

PubMed, Web of Science, Cochrane Library and Embase up to Mar 31, 2019 were searched by two investigators independently using search terms included "tuberculosis", "sputum induction", "induced sputum", "bronchoscopy" and "bronchoalveolar" to identify studies that met the inclusion criteria (see Appendix S1, Supplementary Information, for complete search descriptions). There were no restrictions on language.

\section{Selection criteria}

Studies were selected based on the following inclusion criteria: (1) induced-sputum specimens as the experimental group, whereas bronchoscopic specimens were regarded as the control group; (2) enough data to calculate the outcome data (true positive (TP), false positive (FP), true negative (TN), false negative (FN)); (3) the participants were diagnosed using the gold standard; (4) the gold standard for diagnosis of pulmonary tuberculosis ${ }^{10}$ was defined in the study; (5) sputum induction and bronchoscopy were used to detect pulmonary tuberculosis in the same patient cohorts; (6) sputum induction and bronchoscopy had to be performed at the time of clinical presentation with suspected tuberculosis before administration of anti-tuberculosis therapy. The exclusion criteria were as follows: (1) the diagnostic method for tuberculosis was not sputum induction and bronchoscopy; (2) reviews, case reports, letters, proceedings, or commentaries.

\section{Data extraction}


Two researchers independently extracted the following information from each study: name of study, first author, publication year, country, source of patients, the number of specimens collected, the concentrations of hypertonic saline, the type of nebulizers, the culture techniques, study type, sample size, reference

standard, total number of TB diagnosis, type of bronchoscopic specimens, and outcome data (TP, FP, FN, and TN). Discrepancies were resolved by consensus.

\section{Risk-of-bias assessments}

The analysis of risk of bias and applicability of diagnostic accuracy for the studies included was assessed independently by the two researchers based on the Quality Assessment of Diagnostic Accuracy Studies (QUADAS-2) by RevMan (version 5.3, Cochrane Collaboration, Oxford, UK). QUADAS-2 consists of four sections: patient selection, index test, reference standard, and flow and timing ${ }^{11}$. The studies included were graded as low risk, high risk, or unclear bias based on the following criteria: (1) if the answers to all of the questions for a section were "yes", then the risk of bias was judged as "low"; (2) if any answer to a question in a section was "no," then risk of bias was judged as "high"; (3) the unclear bias was only to be used when insufficient information was provided. Applicability was judged as low, high, or unclear with the above criteria.

\section{Statistical analysis}

Pooled results and corresponding $95 \%$ confidence intervals $(\mathrm{Cl})$ were calculated with a fixed-effects model when heterogeneity was not significant $(P$ value of Cochran-Q of DOR>0.1); otherwise, a random-effects model was applied. The pooled sensitivities (SEN), specificities (SPE), positive likelihood ratio (PLR), negative likelihood ratio (NLR), diagnostic odds ratio (DOR) and 95\% confidence intervals (Cls) were constructed, and the areas under the curves (AUCs) were calculated. $Z$ tests were conducted for direct comparisons of the diagnostic accuracies of sputum induction and bronchoscopic specimens. Heterogeneity among studies was assessed using the $\mathcal{P}$ value, calculated from the Q statistic of the chi-square test $(25-50 \%$, low heterogeneity; $51-75 \%$, medium heterogeneity; greater than $75 \%$, high heterogeneity ${ }^{12}$. Publication bias was assessed using Deeks'funnel plot asymmetry test if necessary, and a $P$ value above 0.05 suggested the absence of publication bias ${ }^{13}$. All statistical analyses were performed using Meta-DiSc Version 1.4, Review Manager Version 5.3 and R3.5.3 $3^{14}$.

\section{Results}

\section{Search results and study characteristics}

The systematic literature searches identified 1809 potentially relevant studies. One thousand seven hundred and eighty two of these studies were eliminated before the full text assessment. Twenty-seven records were screened in full-text articles and five qualified studies were included at last. The selection process was shown in Fig 1. The five qualified studies ${ }^{5-9}$ include a total of 586 cases. All the studies have sufficient data to quantitative synthesis for the mycobacterial culture of induced-sputum specimens and bronchoscopic specimens in the diagnosis of pulmonary tuberculosis, but only three studies have sufficient data on acid-fast bacilli smear ${ }^{5-7}$. Characteristics of those studies were presented in Table 1 . The quality of all the included studies, in terms of risk of bias and applicability concerns, was acceptable according to QUADAS-2 results (Fig. 2).

Quantitative synthesis of mycobacterial culture

The Spearman correlation coefficient and $P$ value of sputum induction were -0.300 and 0.624 respectively, while the Spearman correlation coefficient and $P$ value of bronchoscopy were 0.000 and 1.000 , both of which indicated that there was no significant threshold effect. There was no significant heterogeneity either in sputum induction studies (Cochran-Q of DOR $=5.55 ; p=0.235$ ) or in bronchoscopy studies (Cochran-Q of DOR $=2.71 ; p=0.608$ ). Therefore the SEN, SPE, PLR, NLR and DOR outcomes were pooled. In terms of mycobacterial culture, the SEN, SPE, PLR, NLR and DOR of sputum induction were 0.72 (95\%CI $0.66-0.77), 1.00(95 \% \mathrm{Cl} 0.99-1.00), 57.57(95 \% \mathrm{Cl} 16.89-196.30), 0.26(95 \% \mathrm{Cl} 0.17-0.42)$ and $280.08(95 \% \mathrm{Cl} 58.93-1331.3)$ respectively, whereas the SEN, SPE, PLR, NLR and DOR of bronchoscopy were $0.70(95 \% \mathrm{Cl} 0.64-0.75), 1.00(95 \% \mathrm{Cl} 0.99-1.00), 51.02(95 \% \mathrm{Cl} 14.93-174.32), 0.33(95 \% \mathrm{Cl} 0.26-0.42)$ and $166.43(95 \% \mathrm{Cl} 45.81-604.61)$ respectively(Table. 2 , Fig. 3). Sputum induction had a similar AUC $(0.9564, \mathrm{SE}=0.0749)$ with bronchoscopy $(0.8618, \mathrm{SE}=$ 0.1652) ( $P$ value for difference of AUC between sputum induction and bronchoscopy was 0.602. Fig. 4.a).

\section{Quantitative synthesis of acid-fast bacilli smear}

Only three articles have enough data on acid-fast bacilli smear ${ }^{5-7}$. The Spearman correlation coefficient and $P$ value of sputum induction (Spearman correlation coefficient: $0.500, p$-value $=0.667)$ were same to bronchoscopy, both of which indicated that there was no significant threshold effect. There was no significant heterogeneity either in the sputum induction studies (Cochran-Q of DOR $=3.72 ; p=0.156$ ) or the bronchoscopy studies (Cochran-Q of $\mathrm{DOR}=$ $5.84 ; p=0.054)$. The SEN, SPE, PLR, NLR and DOR outcomes were pooled. The SEN, SPE, PLR, NLR and DOR of sputum induction were 0.35(95\%Cl, 0.29$0.42), 0.99(95 \% \mathrm{Cl}, 0.96-1.00), 12.72 \varangle 95 \% \mathrm{Cl}, 2.14-75.76 \rrbracket, 0.70 \otimes 95 \% \mathrm{Cl}, 0.57-0.85 \rrbracket$ and $18.78 \varangle 95 \% \mathrm{Cl}, 2.79-126.52 \bigotimes$ respectively, whereas the SEN, SPE, PLR, NLR and DOR of bronchoscopy were $0.38(95 \% \mathrm{Cl}, 0.32-0.45), 0.99(95 \% \mathrm{Cl}, 0.96-1.00), 11.92 \varangle 95 \% \mathrm{Cl}, 1.27-112.26 \rrbracket, 0.67 \varangle 95 \% \mathrm{Cl}, 0.48-0.95 \rrbracket$ and $18.22 \varangle 95 \% \mathrm{Cl}$, $1.55-214.55 \rrbracket$ respectively(Appendix S2). There was no significant difference on AUC between sputum induction (0.6016) and bronchoscopy (0.8163; $p$ value for difference of AUC between them was 0.792. Fig. 4.b).

\section{Mycobacterial culture versus acid-fast bacilli smear of sputum induction in the diagnosis of pulmonary tuberculosis}


In the three articles mentioned above ${ }^{5-7}$, we compared the mycobacterial culture with acid-fast bacilli smear of sputum induction in the diagnosis of pulmonary tuberculosis. The SEN and SPE of mycobacterial culture were $0.66(95 \% \mathrm{Cl}, 0.60-0.72)$ and $0.99(95 \% \mathrm{Cl}, 0.98-1.00)$ respectively, whereas the SEN and SPE of acid-fast bacilli smear were $0.35(95 \% \mathrm{Cl}, 0.29-0.42)$ and $0.99(95 \% \mathrm{Cl}, 0.96-1.00)$ respectively. The SEN of mycobacterial culture is higher than acid-fast bacilli smear $(p<0.001)$.

\section{Sensitivity analysis}

\section{The combined AUC results were not materially altered after we sequentially excluded each study (Appendix S3), suggesting that the results were not excessively dependent on a certain study.}

\section{Discussion}

Diagnosis of tuberculosis is still a challenge for those sputum smear negative pulmonary tuberculosis. The purpose of this meta-analysis was to compare the diagnosis value of sputum induction and bronchoscopy in the diagnosis of sputum smear-negative pulmonary tuberculosis. We found that sputum induction has similar diagnostic performance with bronchoscopy in the diagnosis of sputum smear-negative pulmonary tuberculosis, both in terms of acid-fast bacilli smear and mycobacterial culture.

As is well known, bronchoscopy is an important examination for obtaining high quality respiratory specimens in pulmonary infectious disease and also recommended for the diagnosis of pulmonary tuberculosis ${ }^{10,15,16}$. Nevertheless, this technique is invasive, poorly tolerated and costly compared with sputum induction. Additionally, bronchoscopy is not easily available in resource-limited areas and it is not suitable in settings when a large quantity of people need to be evaluated.

Sputum induction is an uncomplicated, safe, cheap, and effective method for the diagnosis of pulmonary tuberculosis, which make it particularly suitable for being used in resource-limited settings ${ }^{4,17,18}$. Several studies have compared detection rates of sputum induction with bronchoscopy in tuberculosis cases. The results are variable and the sample size is relatively small $5,9,19$. Our meta-analysis showed that sputum induction had a similar overall diagnostic accuracy with bronchoscopy in sputum smear-negative pulmonary tuberculosis. Meanwhile, a prospective multicenter study showed that repeated induced sputum specimens can improve the diagnostic yield of pulmonary tuberculosis and it is not desirable to exclude the diagnosis of tuberculosis through a single specimen ${ }^{19}$. The similar result was also found in Charoenratanakul's study ${ }^{20}$. Considering all of these, we suggested that for patients with suspected pulmonary tuberculosis who are smear-negative for acid-fast bacilli, sputum induction rather than bronchoscopy should be recommended as the initial method, which is in accordance with the guideline ${ }^{10}$.

We compared the diagnostic yield of acid-fast bacilli smear with mycobacterial culture of sputum induction in pulmonary tuberculosis, and found that the SEN in mycobacterial culture was higher than in acid-fast bacilli smear, which is consistent with the previous study by Monkongdee et al ${ }^{21}$. Our results are also in line with the new guidelines for pulmonary tuberculosis diagnosis published by World Health Organization (WHO) ${ }^{1}$. So patients with suspected pulmonary tuberculosis who are acid-fast bacilli smear negative should undergo mycobacterial culture to increase the diagnostic yield of tuberculosis.

The limitations in our meta-analysis are as follows. First, the number of included studies was not large. This is because we only accepted studies that used sputum induction and bronchoscopy for detection of tuberculosis within the same population, which is also an advantage of this study because of the small heterogeneity. Second, the different sources of patients suggested that the morbidity varied among studies, which implied the degree of diagnostic of those studies were also different. Third, the culture techniques in the different studies were different, but it is same for the culture of the two specimens (sputum induction and bronchoscopy specimen) in each study. So it doesn't significantly affect the heterogeneity of this study. Fourth, we only compared the diagnostic value of acid-fast bacilli smear or mycobacterial culture of sputum induction or bronchoscopy in tuberculosis, but were unable to compare the acidfast bacilli smear joint mycobacterial culture of sputum induction or bronchoscopy, as there were no sufficient data of this topic for statistical analysis.

\section{Conclusion}

Sputum induction has similar sensitivity, specificity and overall accuracy compared to bronchoscopy-obtained specimens in diagnosing for sputum smearnegative pulmonary tuberculosis. Meanwhile, mycobacterial culture has a higher sensitivity than acid-fast bacilli smear in diagnosing for sputum smear negative tuberculosis.

\section{Declarations}

Acknowledgements: none

\section{Grant Support: Youth Scientific Research Project (2016-2-64) of Fujian Provincial Health Commission and Xiamen Municipal Health Commission in China.}

\section{Disclosure statement: No conflict interests were declared.}




\section{References}

1 WHO. Global tuberculosis report 2018 [Available from: Available: http://www.who.int/tb/ publications/global_report/en.

2 Strumpf IJ, Tsang AY, Sayre JW. Re-evaluation of sputum staining for the diagnosis of pulmonary tuberculosis. Am Rev Respir Dis. 1979;119(4):599-602.

3 Murray PR, Elmore C, Krogstad DJ. The acid-fast stain: a specific and predictive test for mycobacterial disease. Ann Intern Med. 1980;92(4):512-3.

4 Gonzalez-Angulo Y, Wiysonge CS, Geldenhuys H, Hanekom W, Mahomed H, Hussey G, Hatherill M. Sputum induction for the diagnosis of pulmonary tuberculosis: a systematic review and meta-analysis. European journal of clinical microbiology \& infectious diseases: official publication of the European Society of Clinical Microbiology. 2012;31(7):1619-30.

5 Saglam L, Akgun M, Aktas E. Usefulness of induced sputum and fibreoptic bronchoscopy specimens in the diagnosis of pulmonary tuberculosis. The Journal of international medical research. 2005;33(2):260-5.

6 Conde MB, Soares SL, Mello FC, Rezende VM, Almeida LL, Reingold AL, Daley CL, Kritski AL. Comparison of sputum induction with fiberoptic bronchoscopy in the diagnosis of tuberculosis: experience at an acquired immune deficiency syndrome reference center in Rio de Janeiro, Brazil. American journal of respiratory and critical care medicine. 2000;162(6):2238-40.

7 Anderson C, Inhaber N, Menzies D. Comparison of sputum induction with fiber-optic bronchoscopy in the diagnosis of tuberculosis. American journal of respiratory and critical care medicine. 1995;152(5 Pt 1):1570-4.

8 McWilliams T, Wells AU, Harrison AC, Lindstrom S, Cameron RJ, Foskin E. Induced sputum and bronchoscopy in the diagnosis of pulmonary tuberculosis. Thorax. 2002;57(12):1010-4.

9 Prakash P, Agarwal P, Gupta A, Gupta E, Dasgupta A. Comparison of Induced Sputum and Bronchoalveolar Lavage Fluid Examination in the Diagnosis of Sputum Negative Pulmonary Tuberculosis. The Indian journal of chest diseases \& allied sciences. 2016;58(3):173-5.

10 Lewinsohn DM, Leonard MK, Lobue PA, Cohn DL, Daley CL, Desmond E, Keane J, Lewinsohn DA, Loeffler AM, Mazurek GH, O’Brien RJ, Pai M, Richeldi L, Salfinger M, Shinnick TM, Sterling TR, Warshauer DM, Woods GL. Official American Thoracic Society/Infectious Diseases Society of America/Centers for Disease Control and Prevention Clinical Practice Guidelines: Diagnosis of Tuberculosis in Adults and Children. Clinical Infectious Diseases. 2017 ;64(2):e1-e33.

11 Whiting PF, Rutjes AW, Westwood ME, Mallett S, Deeks JJ, Reitsma JB, Leeflang MM, Sterne JA, Bossuyt PM, Group Q-. QUADAS-2: a revised tool for the quality assessment of diagnostic accuracy studies. Ann Intern Med. 2011;155(8):529-36.

12 Higgins JPT, Thompson SG. Quantifying heterogeneity in a meta-analysis. Statistics in Medicine. 2002;21(11):1539-58.

13 Song F, Khan KS, Dinnes J, Sutton AJ. Asymmetric funnel plots and publication bias in meta-analyses of diagnostic accuracy. Int J Epidemiol. 2002;31(1):88-95.

14 Team RC. R: A language and environment for statistical computing. R Foundation for Statistical Computing, Vienna, Austria. 2019.

15 de Gracia J, Curull V, Vidal R, Morell F. Bronchoscopy with bronchoalveolar lavage in the diagnosis of pulmonary tuberculosis. Chest. 1992;101(1):292.

16 Kennedy DJ, Lewis WP, Barnes PF. Yield of bronchoscopy for the diagnosis of tuberculosis in patients with human immunodeficiency virus infection. Chest. 1992;102(4):1040-4.

17 Hepple P, Ford N, McNerney R. Microscopy compared to culture for the diagnosis of tuberculosis in induced sputum samples: a systematic review. The international journal of tuberculosis and lung disease: the official journal of the International Union against Tuberculosis and Lung Disease. 2012;16(5):57988 .

18 Morse M, Kessler J, Albrecht S, Kim R, Thakur R, Nthobatsang R, Radisowa K, Maunatlala C, Yang W, Macgregor RR, Friedman H. Induced sputum improves the diagnosis of pulmonary tuberculosis in hospitalized patients in Gaborone, Botswana. The international journal of tuberculosis and lung disease: the official journal of the International Union against Tuberculosis and Lung Disease. 2008;12(11):1279-85.

19 Schoch OD, Rieder P, Tueller C, Altpeter E, Zellweger JP, Rieder HL, Krause M, Thurnheer R. Diagnostic yield of sputum, induced sputum, and bronchoscopy after radiologic tuberculosis screening. American journal of respiratory and critical care medicine. 2007;175(1):80-6.

20 Charoenratanakul S, Dejsomritrutai W, Chaiprasert A. Diagnostic role of fiberoptic bronchoscopy in suspected smear negative pulmonary tuberculosis. Respiratory medicine. 1995;89(9):621-3.

21 Monkongdee P, McCarthy KD, Cain KP, Tasaneeyapan T, Nguyen HD, Nguyen TN, Nguyen TB, Teeratakulpisarn N, Udomsantisuk N, Heilig C, Varma JK. Yield of acid-fast smear and mycobacterial culture for tuberculosis diagnosis in people with human immunodeficiency virus. Am J Respir Crit Care Med.

2009;180(9):903-8.

\section{Tables}


Table 1. Characteristics of the 5 studies included in the meta-analysis.

\begin{tabular}{|c|c|c|c|c|c|c|c|c|c|c|c|c|}
\hline author & year & Country & $\begin{array}{l}\text { Source of } \\
\text { patients }\end{array}$ & $\begin{array}{l}\text { the } \\
\text { number of } \\
\text { specimens } \\
\text { collected }\end{array}$ & $\begin{array}{l}\text { the } \\
\text { concentrations } \\
\text { of hypertonic } \\
\text { saline }\end{array}$ & $\begin{array}{l}\text { the type } \\
\text { of } \\
\text { nebulizers }\end{array}$ & $\begin{array}{l}\text { the culture } \\
\text { techniques }\end{array}$ & $\begin{array}{l}\text { Study } \\
\text { type }\end{array}$ & $\begin{array}{l}\text { Sample } \\
\text { size }\end{array}$ & $\begin{array}{l}\text { reference } \\
\text { standard }\end{array}$ & $\begin{array}{l}\text { Total TB } \\
\text { diagnosis }\end{array}$ & $\begin{array}{l}\text { type of } \\
\text { bronchoscope } \\
\text { specimens }\end{array}$ \\
\hline Anderson ${ }^{7 *}$ & 1995 & Canada & $\begin{array}{l}\text { tertiary } \\
\text { health care } \\
\text { unit }\end{array}$ & once & $3 \%$ & $\begin{array}{l}\text { DeVilbiss } \\
\text { ultrasonic } \\
\text { nebulizer }\end{array}$ & $\begin{array}{l}\text { Middlebrook agar } \\
\text { or Bactec Culture } \\
\text { Systems }\end{array}$ & PS & 101 & 1 or 2 & 27 & BB1,BB2,BAL \\
\hline Conde ${ }^{6 *}$ & 2000 & Brazil & $\begin{array}{l}\text { primary } \\
\text { health units } \\
\text { or tertiary } \\
\text { health care } \\
\text { unit }\end{array}$ & once & $3 \%$ & $\begin{array}{l}\text { DeVilbiss } \\
\text { ultrasonic } \\
\text { nebulizer }\end{array}$ & $\begin{array}{l}\text { Löwenstein- } \\
\text { Jensen and } \\
\text { Sabouraud's } \\
\text { medium }\end{array}$ & PS & 251 & 1 or 2 & 143 & BAL \\
\hline McWilliams $^{8}$ & 2002 & $\begin{array}{l}\text { New } \\
\text { Zealand }\end{array}$ & $\begin{array}{l}\text { Tuberculosis } \\
\text { specialist } \\
\text { hospital }\end{array}$ & three & $3 \%$ & $\begin{array}{l}\text { DeVilbiss } \\
\text { ultrasonic } \\
\text { nebulizer }\end{array}$ & $\begin{array}{l}\text { Bactec 12B and } \\
\text { Lowenstein- } \\
\text { Jensen media. }\end{array}$ & PS & 129 & 1 & 27 & BAL, BW \\
\hline Saglam $^{5 *}$ & 2005 & Turkey & $\begin{array}{l}\text { tertiary } \\
\text { health care } \\
\text { unit }\end{array}$ & once & $3 \%$ & $\begin{array}{l}\text { ultrasonic } \\
\text { nebulizer }\end{array}$ & $\begin{array}{l}\text { Lowenstein- } \\
\text { Jensen medium }\end{array}$ & PSM & 55 & 1 or 2 & 49 & BAL \\
\hline Prakash $^{9}$ & 2016 & India & $\begin{array}{l}\text { tertiary } \\
\text { health care } \\
\text { unit }\end{array}$ & once & $3 \%$ & nebuliser & $\begin{array}{l}\text { LowensteinJensen } \\
\text { (L-J) medium }\end{array}$ & unclear & 50 & 1 & 35 & BAL \\
\hline
\end{tabular}

*: Sufficient data for both Mycobacterial culture and acid-fast bacilli smear.

PS=prospective study. PMS=Prospective multicenter study.

$1=$ positive culture for Mycobacterium tuberculosis. 2=unequivocal radiographic improvement after adequate treatment with anti-tuberculosis drugs

$\mathrm{BAL}=$ bronchoalveolar lavage, $\mathrm{BW}=$ bronchial washing, $\mathrm{BB} 1=$ bronchial brushings, $\mathrm{BB} 2=\mathrm{Bronchial}$ biopsies .

Table 2. Pooled results of sputum induction and bronchoscopy mycobacterial culture.

\begin{tabular}{llllll}
\hline & $\begin{array}{l}\text { Pooled SEN } \\
(95 \% \mathrm{CI})\end{array}$ & $\begin{array}{l}\text { Pooled SPE } \\
(95 \% \mathrm{CI})\end{array}$ & $\begin{array}{l}\text { Pooled +LR } \\
(95 \% \mathrm{CI})\end{array}$ & $\begin{array}{l}\text { Pooled -LR } \\
(95 \% \mathrm{CI})\end{array}$ & $\begin{array}{l}\text { Pooled DOR } \\
(95 \% \mathrm{CI})\end{array}$ \\
\hline sputum induction & 0.72 & 1.00 & 57.57 & 0.26 & 280.08 \\
& $(0.66-0.77)$ & $(0.99-1.00)$ & $(16.89-196.30)$ & $(0.17-0.42)$ & $(58.93-1331.3)$ \\
Broncho- & 0.70 & 1.00 & 51.02 & 0.33 & 166.43 \\
& $(0.64-0.75)$ & $(0.99-1.00)$ & $(14.93-174.32)$ & $(0.26-0.42)$ & $(45.81-604.61)$ \\
\hline
\end{tabular}

\section{Figures}


Figure 1. Procedure used for selection of studies (PRISMA flow diagram).
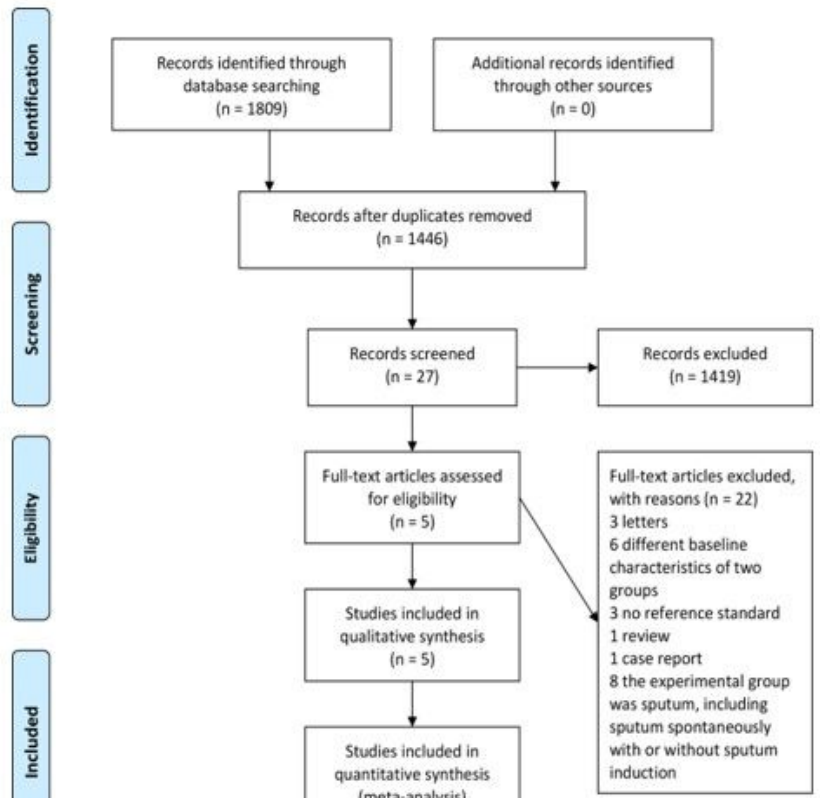
(meta-analysis) $(n=5)$

Figure 1

Procedure used for selection of studies (PRISMA flow diagram).

Figure 2. Quality assessment of the included studies (QUADAS-2).

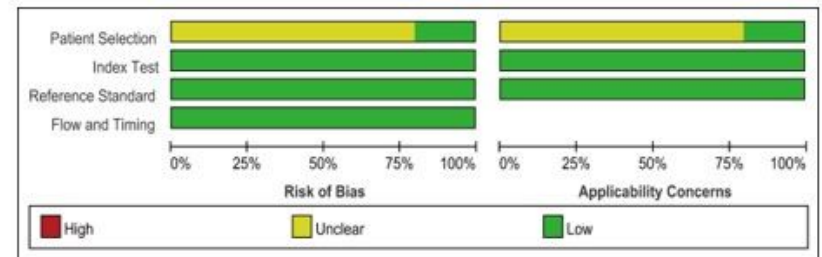

\begin{tabular}{|c|c|c|c|c|c|c|c|}
\hline & \multicolumn{4}{|c|}{ Risk of Bias } & \multicolumn{3}{|c|}{ Applicability Concerns } \\
\hline & 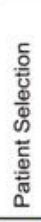 & 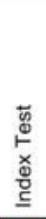 & 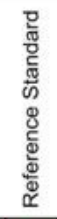 & 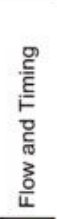 & 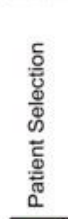 & 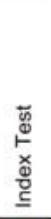 & 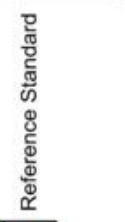 \\
\hline Anderson 1995 & $\odot$ & $\odot$ & $\odot$ & + & $\odot$ & $\odot$ & $\odot$ \\
\hline Conde 2000 & $?$ & + & + & + & $?$ & + & + \\
\hline McWilliams 2002 & $?$ & + & + & + & $?$ & + & + \\
\hline \multirow{2}{*}{$\begin{array}{l}\text { Prakash } 2016 \\
\text { Saglam } 2005\end{array}$} & $?$ & 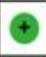 & + & + & $?$ & $\odot$ & + \\
\hline & $?$ & $\odot$ & $\odot$ & + & $?$ & $\odot$ & $\odot$ \\
\hline$O_{\text {High }}$ & & & Unc & clear & & & Low \\
\hline
\end{tabular}

Figure 2 
Quality assessment of the included studies (QUADAS-2).

Figure 3. SEN and SPE of sputum induction VS bronchoscopy on mycobacterial culture.

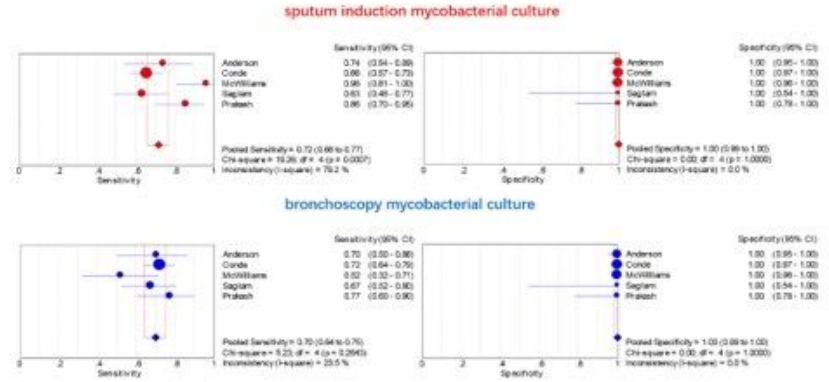

\section{Figure 3}

SEN and SPE of sputum induction VS bronchoscopy on mycobacterial culture.

Figure 4. ROC of sputum induction VS bronchoscopy on mycobacterial culture(Fig. 4.a) and

acid-fast bacilli smear(Fig.4.b)
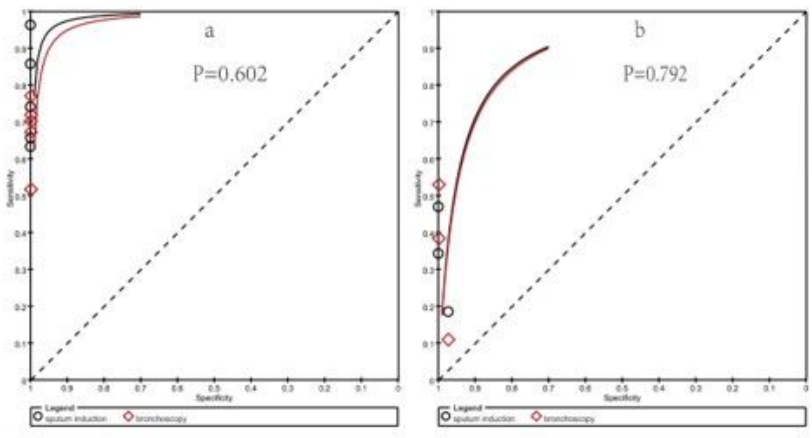

\section{Figure 4}

ROC of sputum induction VS bronchoscopy on mycobacterial culture(Fig. 4.a) and acid-fast bacilli smear(Fig.4.b).

\section{Supplementary Files}

This is a list of supplementary files associated with this preprint. Click to download.

- PRISMA2009ChecklistMSWord.doc

- SUPPLEMENTARYINFORMATIONtext.docx 